\title{
Los intercambios y el dinero desde una perspectiva liberal
}

\section{Exchanges and Money from a Liberal \\ Perspective}

\author{
Ricardo Romero García \\ https://orcid.org/0000-0002-0267-9374 \\ ricardo.romero.garcia@gmail.com \\ Jorge Moreno Purroy \\ https://orcid.org/0000-0003-0111-4168 \\ jorge8mp8@gmail.com
}

\section{Resumen}

En tanto una sociedad libre debe fundamentarse en intercambios voluntarios, veremos en qué consisten estos y los definiremos, desarrollando sus dos tipos: el directo, con sus limitaciones, y el indirecto, con los beneficios que conlleva. Los indirectos necesitan de un medio para su ejecución, el dinero, que definiremos estudiando su origen y las características que han de cumplirse para que un medio de intercambio pueda ser efectivamente considerado como dinero. Señalaremos los tipos de dinero, la importancia que tienen en la formación de los precios y estudiaremos la determinación del poder adquisitivo del propio dinero. Se señalará por qué pensamos que las criptomonedas no pueden ser consideradas como dinero, y se terminará el artículo con las características que debería poseer el dinero en una sociedad libre. 
Palabras clave: escuela austriaca, intercambios, dinero, tipo de interés, precios, historia económica.

Códigos JEL: B25, D40, E40, E43.

\section{Abstract}

As a free society must be based on voluntary exchanges, we will see what they consist of and define them, developing their two types: direct voluntary exchanges, with their limitations, and the indirect ones, with the benefits they entail. Indirect ones need a means for their execution, money, which we will define, studying its origin and the characteristics that must be accomplished so that a means of exchange can be considered as money. We will point out the types of money, and the importance they have in the formation of prices, and also observe the determination of the purchasing power of money itself. It will be pointed out why we think that cryptocurrencies cannot be considered as money, and the work will be finished with the characteristics that money should have in a free society.

Keywords: Austrian school, exchanges, money, interest rate, prices, economic history.

JEL Codes: B25, D40, E40, E43.

\section{Introducción}

Por medio del presente estudio se va a intentar explicar la importancia que han tenido los intercambios en el desarrollo de la sociedad. Se verá cuán determinante fue la aparición de los medios de intercambio para solventar el problema de la doble coincidencia de necesidades que traía consigo el intercambio directo.

Se desarrollarán las causas por las que algunos medios de intercambio pueden llegar a convertirse en dinero, para después considerar en qué consiste y por qué hay elementos que si bien se denominan dinero podrán ser medios de pago, pero no dinero como tal. Una vez definido qué entendemos por dinero, se pasará a exponer su alcance a la hora de efectuar la determinación de los precios. Se señalará la importancia que tiene en el mercado lo que es posiblemente el precio más relevante, esto es, el tipo de 
interés, y la trascendencia que tiene en las transacciones. En el penúltimo punto se verán las características básicas de las criptomonedas y los factores que permiten señalar que el día de mañana podrán llegar a ser medios de pago, pero no dinero.

Antes de las conclusiones, y para finalizar, se indicará cómo podría desarrollarse la institución social del dinero una vez que volviera a manos de los ciudadanos, esto es, en una sociedad libre.

\section{Los intercambios}

El ser humano actúa para cumplir deseos o necesidades insatisfechas; con su actuación busca cambiar una situación por otra que subjetivamente considera le resultará más satisfactoria.

Ese cambio buscado puede conseguirse, bien de forma personal, esto es, sin contar con la ayuda de terceros, como por ejemplo, el ermitaño que caza para su propia supervivencia, o, por el contrario, el individuo puede buscar satisfacer sus necesidades por medio de la interacción con otros seres humanos, por ejemplo, cuando un cazador ya no atrapa sus piezas solo para poder sobrevivir él, sino que lo hace para intercambiarlas por otro bien o servicio que necesite o valore más que su pieza de caza en ese momento (Mises, 2011).

El principio que estimula al ser humano a intercambiar es el mismo que rige toda su actividad económica, que no es otro que el deseo de satisfacer sus necesidades de la manera más perfecta posible (Menger, 1996).

Constituye un error pensar que en un intercambio ambas partes han de recibir una cantidad igual de valor, puesto que para que se produzca cualquier tipo de intercambio voluntario cada una de las partes debe valorar más lo que pretende adquirir que aquello de lo que está dispuesto a desprenderse. Por lo tanto, un intercambio voluntario tendrá lugar única y exclusivamente en la medida en que ambas partes tengan la esperanza de que conseguirán un beneficio con el cambio. Por ejemplo, si el sujeto A intercambia unas zapatillas por un abrigo que pertenece al sujeto $B$, en este caso, el sujeto $A$ valorará subjetivamente más el abrigo que obtiene que las zapatillas de las que se desprende, y viceversa, en el caso del sujeto B. Esta idea, que parece tan elemental, no supo ser captada en esencia por mentes tan lúcidas como la de Aristóteles, quien entendía que si se producía un 
intercambio entre dos bienes se debía a que existía algún tipo de igualdad entre la valoración de bienes intercambiados. Craso error, pues todo intercambio es producto de la desigualdad de valoraciones en sentido contrario entre dos actores.

Tiene que resultar claro en este punto que las valoraciones son subjetivas, que están vinculadas a la necesidad sentida por los actores, y que no permanecen fijas con el transcurso del tiempo; por ejemplo, si una persona lleva dos días sin comer, valorará mucho un trozo de pan, por el miedo a perecer por inanición, pero si, por el contrario, tiene la suerte de comer varias veces al día, la valoración que dará a ese mismo trozo de pan seguramente sea bastante inferior.

\section{El intercambio directo}

Las relaciones interpersonales pueden tener lugar por dos vías: por medio del uso de la violencia, la amenaza de esta o la intimidación, siendo este un tipo de relación a las que Mises calificó como hegemónica; o por las relaciones de intercambio voluntario, que se caracterizan por la ausencia de las restricciones o limitaciones que están en la base de las relaciones hegemónicas o de explotación (Rothbard, 2011).

Para que una persona pueda intercambiar un bien, en primera instancia habrá de poseerlo, y objetos de posesión serán aquellos considerados escasos o bienes económicos, dado que los bienes que sean sobreabundantes o libres estarán fuera del comercio entre los hombres; el ejemplo típico de bien libre es el aire que respiramos, que al no ser escaso no es objeto de intercambio.

El intercambio directo se enfrenta a las siguientes dificultades:

- Satisfacer la doble coincidencia de necesidades, esto es, si el sujeto A ofrece un bien o servicio (por ejemplo, es panadero), todo aquel que quiere intercambiar con él deberá ofrecerle un bien o servicio que A esté dispuesto a aceptar a cambio del suyo.

- Otros impedimentos surgen de la indivisibilidad de los bienes, dado que algunos no pueden llegar a subdividirse para acomodarse a la satisfacción de las necesidades. Pongamos por caso que el sujeto $A$ tiene una casa que desea intercambiar por un coche que tiene el sujeto $B$, una motocicleta que tiene el sujeto $C$ y una bicicleta que tiene el sujeto $D$ : para lograr ello no podría darle a uno el dormitorio y el baño, a otro la cocina y el salón, y al tercer sujeto la 
otra habitación y la terraza, todo ello en pago de los distintos bienes que desea obtener a cambio del suyo.

Si bien el intercambio directo fue muy importante para la sociedad, dado que conllevó que se pasara de intercambios violentos y coercitivos a intercambios voluntarios, fue gracias a la aparición de los intercambios indirectos que se produjo el avance y el gran desarrollo de la civilización.

\section{El intercambio indirecto}

En los mecanismos de intercambio indirecto no se produce una transacción directa de bienes o servicios que se tienen y ofrecen por otros que se desean obtener, sino que el intercambio se efectúa de manera indirecta por medio de otro bien; esto es, se venden productos o servicios a cambio de ese bien intermedio, que a su vez se vuelve a utilizar a posteriori para obtener, ahora sí, aquello que se desea para satisfacer alguna de las infinitas necesidades del ser humano.

La aparición de un medio de intercambio generalizado da una mayor oportunidad para comerciar con los distintos productos que se ofrecen en el mercado, ya que no existen las limitaciones que se enfrentan en el intercambio directo, lo que contribuye al progreso material de la sociedad en su conjunto.

Estos bienes intermedios se caracterizaron en su momento por ser los más demandados por la sociedad en su conjunto en ese período y lugar concretos. A lo largo de la historia se han dado distintos tipos de bienes que eran más comercializables que otros, teniendo la tradición una gran importancia en la designación de un bien como medio de intercambio. Podemos observar a modo de ejemplo que en tribus nómadas la cabeza de ganado resultaba un medio de intercambio común en las transacciones y en pueblos más sedentarios se tiene constancia del uso como medio de intercambio de bienes como el trigo o el cacao, por ejemplo. Otros medios que se han utilizado históricamente, a modo enunciativo, podrían ser la sal, las pieles, el algodón, las conchas marinas o el arroz, todos ellos caracterizados por su mayor comerciabilidad en un momento y lugar determinados.

Cuando la industria fue adquiriendo relevancia, metales como el cobre o el hierro se utilizaron como dinero, pero al desarrollarse el comercio entre zonas cada vez más distanciadas empezaron a utilizarse metales cada vez más preciosos, especialmente el oro y la plata, que hasta ese punto se utilizaban simplemente como ornamentación (Aguirre, 2019). 
Señala Rothbard (2015) que dentro de la comerciabilidad de los bienes:

Some goods are more widely demanded than others, some are more divisible into smaller units without lost of value, some more durable over long periods of time, some more transportable over large distances. All of these advantages make for greater marketability. It is clear that in every society, the most marketable goods will be gradually selected as the media for exchange (pp. 7-8).

Estos bienes que gozaban de una mayor comerciabilidad, y ostentaban una mayor capacidad de venta, fueron denominados por los germanos Geld ('dinero'), palabra derivada de gelten, que significa 'valer', 'tener validez', 'ser válido'. Se observa así que, en alemán, el término dinero se refiere a aquel medio que sirve para pagar (Menger, 1996).

Algunas de las razones (Rallo, 2015) que ayudan a que una mercancía sea más comercializable que otra son las siguientes:

- Una demanda más extensa e intensa.

- Que no sea susceptible de experimentar fluctuaciones muy violentas.

- Que perdure en el tiempo.

- Que pueda fraccionarse.

\section{Definición, origen y características del dinero}

Podemos entender por dinero, siguiendo la definición del profesor Martínez-Meseguer (2015b, p. 106), a aquella "institución social evolutiva, consistente en todo bien económico (material) que, teniendo atribuido subjetivamente valor de uso y valor de intercambio, es común y libremente aceptado como medio de pago por una sociedad (o colectivo)".

Caracterizado entonces como institución social, debe entenderse que este no ha sido creado de forma deliberada por nadie, siendo por tanto un resultado no intencional, que se ha ido originando paulatinamente debido a la confluencia de distintos intereses y de diferentes actores. Aunque

Algunos bienes tienen más demanda que otros, algunos son más divisibles en unidades más pequeñas sin pérdida de valor, algunos más duraderos durante largos períodos de tiempo, algunos más transportables a grandes distancias. Todas estas ventajas contribuyen a una mayor comerciabilidad. Está claro que en todas las sociedades, los bienes más comercializables se seleccionarán gradualmente como medios de intercambio. 
también es cierto que el fenómeno de intentar retrotraer el origen del dinero a un acto legislativo ha sido una cuestión recurrente a lo largo de la historia, y Menger (2006) recoge por ejemplo que Platón en La república ya señalaba que el dinero es "un signo convencional para el intercambio" ( $p$. 229), o que Aristóteles afirmaba que el dinero surgió por convención, esto es, no por vía natural sino mediante una ley.

Cabe señalar que si Platón o Aristóteles estuvieren en lo cierto habría algún tipo de constancia documental histórica de la imposición del dinero por vía de decreto, pero hasta el momento no ha aparecido ninguna noticia por la que se pueda acreditar que tal origen del dinero se materializó de hecho por mandato legal. Ha sido más bien la costumbre, junto a la práctica y a la imitación por parte del resto de seres humanos, lo que ayudó a transformar las mercancías que tenían la cualidad de ser más comercializables en un medio de cambio de uso generalizado. En palabras de Wilhelm Röpke (1974, p. 100), para que un bien se pudiera considerar dinero debía cumplir la condición previa de "ser, con carácter general, intercambiable y aceptable como medio de pago", además de que esa aceptación como medio de pago debe realizarse con carácter subjetivo por parte de los actores.

No cabe duda de que el origen del dinero es cuanto menos misterioso, en el sentido apuntado por Menger (1985), al señalar:

[...] que cada hombre económico, en cualquier país, acepte cambiar sus bienes por pequeños discos metálicos aparentemente carentes de utilidad como tales, o por documentos que los representen, es un procedimiento tan opuesto al curso normal de los acontecimientos que no puede parecernos sorprendente que hasta un pensador tan distinguido como Savigny lo encuentre claramente "misterioso" (p. 1).

Pero el mismo autor no tiene duda alguna de su procedencia, cuando señala que "el dinero no es una creación de la ley; no es un fenómeno de origen estatal, sino un fenómeno de origen social" (2013, p. 135).

Siguiendo a Rothbard (2013), se ha de reseñar que fue el monje franciscano Buridiano (1300-1358) el que abandonó la concepción aristotélica del origen del dinero, fundando la conocida como teoría metalista del dinero, que consiste en considerar que este nace siendo en primera instancia una mercancía útil, por medio de las interacciones voluntarias entre los integrantes del mercado, quienes de forma espontánea y por costumbre terminan eligiendo dicha mercancía como medio de cambio, siendo casi siempre un metal el elegido, principalmente el oro o la plata, dadas sus propiedades particulares. 
¿Y cuáles son esas propiedades o características que se han de ostentar para poder ser considerado un "buen dinero"? En la línea de Franch-Parella (2012) podemos señalar las siguientes:

- Que goce de una demanda universal.

- Que sea un bien escaso.

- Que sea divisible.

- Tiene que ser homogéneo.

- Ha de ser transportable.

- Debe ser duradero.

- Difícilmente falsificable.

Respecto de las funciones que puede desempeñar el dinero, y según Rothbard (2015, p. 10), "money has several functions: a medium of exchange, unit of account, or 'measure of values', a 'store of value,' etc. But it should be clear that all of these functions are simply corollaries of the one great function: the medium of exchange".2.

En suma, no será la cantidad de dinero disponible en una sociedad la que la convierta en más o menos rica. Será la mayor abundancia de bienes de capital la que lo haga, dado que el nivel de productividad será más alto cuantos más bienes de capital se utilicen en el proceso de producción. En eso consiste la principal diferencia entre las sociedades ricas y pobres: las personas de un país más industrializado no son ni más inteligentes ni más trabajadoras que las de otro país en vías de desarrollo; la diferencia principal son los recursos que utilizan en el desempeño de su trabajo, dado que no es lo mismo trabajar un campo con un tractor de última generación que con un arado tirado por bueyes.

\section{Tipos de dinero}

Antes de definir las tres categorías de dinero que se han determinado hay que señalar que el único tipo que puede considerarse como tal propiamente es el calificado como dinero material, dado que solo este cumpliría con los requisitos señalados anteriormente; en cuanto al dinero crediticio, 
según la definición misma de dinero, debería entenderse mejor como medios de intercambio crediticios (letra de cambio, pagaré, etc.), respaldados por un soporte material, que ayudan al intercambio. Por último se encuentra el dinero fiduciario, que se origina vía mandato y el único respaldo que tiene es el que se quiera dar a la entidad u organismo que lo emite.

\section{Dinero material}

Previamente se ha señalado cómo aquellos bienes que gozaban de una mayor capacidad de intercambio se fueron convirtiendo por medio de la costumbre, sin necesidad de medida legislativa alguna, en el medio de intercambio aceptado por todos.

Buridiano, adelantándose a Menger y Mises, señaló que para que pudiera usarse como moneda de cambio un bien debía estar constituido por un material que ya de por sí gozara de valor, con independencia de su función monetaria, y por tanto "debía ser una mercancía originalmente útil para propósitos no monetarios" (Rothbard, 2013, p. 105).

En palabras de Hülsmann (2008):

To be spontaneously adopted as a medium of exchange, a commodity must be desired for its nonmonetary services (for its own sake) and be marketable, that is, it must be widely bought and sold [...] it is important to keep in mind that the monetary use of a commodity ultimately depends on its nonmonetary use $e^{3}$ (p. 23).

Haciendo uso de su perspicacia, el ser humano llegó a descubrir que determinados bienes no solo tenían utilidad de por sí, ya fuera como bienes de consumo o como factores de producción, sino que dada su alta demanda podrían ser utilizados como medios de intercambio; si bien hubo distintos ejemplos de dinero material o mercancía a lo largo del tiempo, desde conchas a cacao, cereales o sal, los que mejores características ostentaban, como hemos señalado en la sección anterior, fueron los metales preciosos, y en especial el oro y la plata.

Una de las características fundamentales de estos metales resultó ser su escasez natural respecto a su demanda y el hecho de que, comparados con otros metales, no necesitan seguir un procedimiento excesivamente complejo a efectos de su extracción y elaboración. Por otra parte, también 
presentaron inconvenientes, como la exigencia de transportarlos consigo a la hora de realizar las transacciones, con los consecuentes peligros que ello conllevaba, así como la necesidad de tener los medios indispensables para poder comprobar la pureza del metal y fraccionarlo en la cantidad precisa en cada circunstancia, de ahí que los comerciantes tuvieran que ir en principio cargados habitualmente con distintos pesos y balanzas. Parte de estos problemas se solventaron por medio de la acuñación, que permitió el no tener que ir con básculas e instrumentos para fraccionar el metal precioso, dado que se garantizaba directamente el grado de pureza y el peso del metal; la gran ventaja de la acuñación resultó ser que "los metales destinados a hacer de dinero son susceptibles de convertirse en materia de obligaciones genéricas y cantidades deudoras de contenido exactamente determinado, puntual y fácilmente liquidables (en metal amonedado) con un simple cómputo" (Menger, 2013, p. 129).

\section{Dinero crediticio}

A diferencia del dinero calificado como "material", este dinero crediticio, o papel moneda, se caracteriza por no gozar de valor de uso como objeto de por sí, sino que se limita a representar, por medio de recibos, cantidades determinadas de dinero que se encuentran respaldadas por la entidad emisora y que serán transferidas al momento de la entrega por parte del poseedor del recibo a la entidad emisora.

La primera constancia que se tiene de la utilización de papel moneda se encuentra en China y data de alrededor del siglo IX de nuestra era. En Europa, la utilización del dinero crediticio es mucho más tardía, y surgió casi cinco siglos más tarde, gracias a la actuación de los orfebres, especuladores y cambistas de moneda, quienes por medio del ofrecimiento del servicio de guarda y custodia del oro y de otros metales valiosos de los ciudadanos, a cambio del pago de una cantidad estipulada, se convirtieron en los primeros banqueros. El modo de proceder era muy sencillo y requería de los depositantes plena confianza en el orfebre; luego de entregar su oro los primeros recibían un vale de papel, elemento más seguro ante posibles robos, cómodo y manejable de transportar, evitando así tener que desplazar, en su caso, grandes cantidades de metal.

Cuando alguien le presentaba el vale al orfebre, este tenía la obligación de devolver el oro que se le había previamente depositado, esto es, dado que el papel moneda otorgaba a quien lo portara el derecho a retirar la cantidad de oro que allí constaba, dicho elemento se empezó a usar cada 
vez con más frecuencia como medio de intercambio en las transacciones en lugar del oro.

\section{Dinero fiduciario}

Este es el tipo de dinero que hoy día se utiliza en la sociedad (euro, dólar, libra esterlina, etc.). A diferencia del dinero material o el crediticio, este no apareció de forma espontánea, sino que es producto de la intervención de los dirigentes políticos y financieros en el devenir del mercado, que de forma monopolística se arrogan la potestad de emitir dinero, siendo por tanto un dinero que ya no se basa en la confianza sino en la imposición coactiva de los distintos Estados, que conservan su monopolio de emisión.

Si recordamos la definición que dimos anteriormente, veremos que lo que hoy utilizamos supuestamente como "dinero" es todo menos eso, dado que:

- No ha surgido de manera evolutiva, sino que ha sido impuesto vía decreto gubernamental.

- No es un bien económico, dado que no está sujeto a la limitación de la escasez.

- No tiene atribuido subjetivamente ningún valor de uso o intercambio.

- Y no es común y libremente aceptado como medio de pago, sino que es impuesto de manera forzosa.

Siguiendo a Martínez-Meseguer (2015b), podemos señalar que si no hay patrón material no habrá dinero como tal. Podrá existir algo que se utilice como medio de pago, o medio de intercambio, pero no habrá algo a lo que podamos denominar en puridad como dinero.

\section{El dinero y la determinación de los precios}

Si bien es cierto que en un lugar y momento determinado los bienes poseen unos determinados precios, que los distintos agentes podrán utilizar para el intercambio de los mismos, hay que tener en consideración que la duración de esos precios es muy efímera, puesto que no son magnitudes fijas, sino que van variando. 
Menger (1996, p. 242) recoge que Turgot, en sus Reflexiones sobre la formación y distribución de las riquezas (1770), llegó a la conclusión de que "entre todas las posibles medidas de valor de intercambio, el dinero era la más adecuada y generalizada".

Pero una cosa debe quedar clara en la relación al dinero, y es que, como señala Rothbard (2015, p. 12), "money does not 'measure' prices or values; it is the common denomination for their expression. In short, prices are expressed in money; they are not measured by it".

Aunque se sabe que no será posible que se produzca la equivalencia entre bienes en el sentido objetivo de la palabra, pues todas las valoraciones son subjetivas, el dinero es la mercancía en que se reflejan las valoraciones de los distintos bienes, de ahí que se le denomine como la medida de los precios.

Y, ¿cómo se determinan los precios? Para ello lo mejor es acudir a Eugen von Böhm-Bawerk (2005) y su ley básica de determinación del precio, la cual señala que el precio de mercado se determinará en un punto entre un margen acotado y determinado por las valoraciones que ofrezcan las parejas marginales. ¿En qué consisten las parejas marginales? Pues bien, serán aquellas parejas que se formarán donde exista competencia bilateral, esto es, allí donde haya más de un vendedor y de un comprador potencial. Una de las parejas formará el límite superior, determinada por las valoraciones del último comprador que llegue a un acuerdo y del potencial vendedor que quede excluido y que tuviere la siguiente mayor capacidad de intercambio. El límite inferior lo determinará la otra pareja, dada por las valoraciones del último vendedor que llegó a un acuerdo y del comprador potencial que quedó fuera del acuerdo, y que contaba con la siguiente mayor capacidad de cambio.

La determinación del valor y del precio de las cosas es fruto siempre de las valoraciones subjetivas que se efectúan sobre productos acabados que se encuentran disponibles en el mercado, porque es ahí, "en el mercado, donde cada factor de producción tiene su precio, [lo que] permite el cálculo económico. El cálculo económico maneja precios, nunca valoraciones" (Mises, 2011, p. 404). El mercado posibilita la conexión entre los distintos bienes por medio de los precios, nunca de las valoraciones, que sabemos que son subjetivas.

4 El dinero no "mide" precios ni valores; es la denominación común para su expresión. En resumen, los precios se expresan en dinero; no se miden por ellos. 
Antes de gastar dinero en cualquier bien o servicio una persona hará una comparación entre la utilidad que le ofrece esa posible adquisición frente a la opción de mantener el dinero, y el resultado de esa comparación determinará la escala valorativa subjetiva de cada uno, que unida a la del resto de participantes en el mercado será determinante a la hora de configurar la oferta y demanda de los bienes y de los precios monetarios de estos.

\section{La determinación del valor del dinero}

Ya se ha señalado que el dinero es un medio de intercambio comúnmente aceptado, y su poder adquisitivo, como el de cualquier otro bien, vendrá determinado por la oferta y la demanda de este, de modo que un aumento de la cantidad de dinero disponible, también conocida como inflación, producirá una reducción de su poder adquisitivo. De igual forma, una disminución de la cantidad de dinero, conocida como deflación, provoca un aumento de dicho poder adquisitivo. Así, la característica definitoria del dinero es su poder adquisitivo, esto es, el conjunto de bienes y servicios que pueden comprarse por término medio con cada unidad monetaria.

Pero, como señala Rothbard (2011), la utilidad marginal del dinero se basa en la existencia previa de una diversidad de precios monetarios, demandándose y considerándose útil debido a ese hecho previo. Por tanto, la demanda de todo medio de intercambio viene a ser la resultante de dos demandas parciales: la de aquellos que pretenden emplearlo para el consumo o la producción (se recuerda que el verdadero dinero será aquel que en primera instancia se utiliza por los servicios que presta de por sí, aquel que antes se ha calificado como dinero material) y la de quienes pretenden utilizarlo como medio de intercambio.

A su vez, la amplitud de la demanda del medio de intercambio depende del valor de cambio que el propio dinero tenga en el mercado, esto es, de su precio.

Parecería que nos enfrentamos ante un razonamiento circular, puesto que el precio del dinero viene determinado por su oferta y su demanda en el mercado, y su demanda está determinada en función de su poder adquisitivo, esto es, de su precio. Pero Mises, en la obra La teoría del dinero y el crédito (1912), resolvió este aparente razonamiento con su teoría regresiva del dinero, al señalar que:

- El precio o poder adquisitivo del dinero viene determinado por la oferta y la demanda de este. 
- La demanda de dinero no viene determinada por su poder adquisitivo hoy, sino por la información pasada que el actor tiene sobre el poder adquisitivo que el dinero tuvo ayer.

- El poder adquisitivo que el dinero tuvo ayer viene determinado a su vez por la demanda de dinero basada en el conocimiento que se tenía respecto de su poder adquisitivo de anteayer.

- Este proceso se aplica sucesivamente hasta retrotraerse hasta la primera vez que se utilizó el dinero como medio de intercambio, punto en el que su poder adquisitivo procedería únicamente de su función no monetaria.

Salvado el supuesto razonamiento circular por la teoría de Ludwig von Mises, se ha de recalcar que el precio del bien dinero se conforma tanto por el componente monetario como por el no monetario, dependiendo el primero en última instancia del segundo. Tanto es así, que Hülsmann (2021) señala cómo ya los escolásticos medievales denominaban al dinero: res fungibilis et primo uso consumptibilis ('algo que es fungible ${ }^{5}$ y que principalmente se usa en el consumo').

\section{La tasa o tipo de interés, desde el punto} de vista de la escuela austriaca

Para comprender el dinero y su verdadera utilidad en el pasado y en las actuales sociedades debemos introducir el concepto de tipo de interés. Nos vamos a basar en las explicaciones y matizaciones realizadas por el profesor Jesús Huerta de Soto en sus obras La escuela austriaca, mercado y creatividad empresarial (2000) y La esencia de la Escuela Austriaca (2012).

Si partimos de un enfoque praxeológico, en su escala valorativa el ser humano estima siempre más ceteris paribus los bienes presentes que los bienes futuros, si bien debemos matizar que la intensidad de tales valoraciones subjetivas varía mucho de unos individuos a otros. Y no solamente sucede esto entre los distintos individuos, sino que incluso para una misma persona estas valoraciones pueden ir cambiando a lo largo de su vida.

Se puede afirmar entonces que los seres humanos podemos tener una preferencia temporal baja, o bien otra más alta: en el primer caso estaremos dispuestos a renunciar a bienes presentes a cambio de conseguir bienes

5 Entendiendo por fungibles las cosas que pueden sustituirse por otras de la misma categoría, esto es, que no se tienen en consideración de manera individual, sino en cantidad, peso o por número de medida (Huerta-de-Soto, 2016). 
futuros; en cambio, en el segundo caso valoraremos con más intensidad el presente que el futuro.

Llegado este punto, podemos definir la tasa o tipo de interés como el precio de mercado de los bienes presentes en función de los bienes futuros. Por lo tanto, el término queda establecido por el marco de preferencia temporal de los individuos.

Es en este mercado de bienes presentes y futuros donde se determina el tipo de interés, el precio. Dicho mercado está conformado, por un lado, por los vendedores, es decir, los oferentes de bienes presentes, que son los ahorradores; por otro lado están los compradores, o demandantes de bienes presentes, es decir, todos aquellos que consumen bienes y servicios inmediatos.

Es muy importante señalar que este mercado se constituye por toda la estructura productiva de la sociedad, aspecto de vital importancia para entender el funcionamiento de la actividad económica en su conjunto, en la que los ahorradores o capitalistas renuncian al consumo inmediato y ofrecen bienes presentes a los propietarios de los factores de producción. Una vez más, se pone de manifiesto la necesidad de que unos agentes sacrifiquen consumo presente por futuro, siempre y cuando dicha decisión sea eficiente y rentable en términos económicos.

Debe aquí introducirse el mercado de créditos para entender el funcionamiento de los agentes prestatarios y prestamistas de fondos. Para la escuela austriaca, el mercado de créditos es aquel mercado en el que se pueden obtener préstamos (fondos), que podrán tener diferentes plazos, pagando un determinado tipo de interés. Este mercado es solo una parte del mercado de bienes presentes y futuros, pero a pesar de que no es muy importante y desempeña un papel secundario en dicho mercado, desde el punto de vista público es en cambio más claro y visible. Este aspecto puede llegar a resultar paradójico, en tanto que el ser "más conocido" no lo hace "más significativo."

La paradoja de toda esta exposición (y a nuestro entender la dificultad del análisis y posterior síntesis de estos conceptos) radica en el hecho de que el tipo de interés crediticio es el único importe visible en el mundo exterior, el único que podemos visualizar en el mercado, si bien los beneficios contables brutos también son otro dato económico que podemos percibir con nitidez en el mercado.

Como explica el profesor Huerta de Soto, los beneficios contables brutos son directamente visibles en el mundo exterior, y además se obtienen 
en la actividad productiva específica dentro de cada etapa del proceso de producción, señalándose que tienden a igualarse al tipo de interés bruto o de mercado.

Huerta de Soto continúa su razonamiento indicando que por eso es posible que una empresa aun obteniendo beneficios contables en realidad esté en pérdidas empresariales, si es que dichos beneficios contables no alcanzan el importe necesario para superar el coste de oportunidad implícito (descontado) de tipo de interés bruto de mercado, aplicado sobre los recursos (fondos) invertidos por los capitalistas en su negocio, a lo largo del ejercicio económico.

Para nosotros, otra cuestión fundamental es la relación que se produce entre el ahorro y el tipo de interés de mercado. Cuanto mayor sea el ahorro, es decir, cuantos más bienes presentes se ofrezcan (vendan), ceteris paribus, más bajo será su precio en términos de bienes futuros, y más bajo será el tipo de interés de mercado. En cambio, cuanto menor sea el ahorro, y cuanto menos estén los agentes económicos dispuestos a renunciar al consumo inmediato de bienes presentes (oferta), más alto será el tipo de interés de mercado.

Como corolario, podemos señalar que el tipo de interés es aquella señal que indica a los empresarios qué nuevas etapas productivas o proyectos de inversión pueden acometer y cuáles tienen que rechazar, con el fin de mantener coordinados los comportamientos, tanto de ahorradores como de consumidores e inversores.

\section{Las criptomonedas}

Las criptomonedas son un tipo de monedas digitales independientes y descentralizadas que pretenden convertirse en un medio de pago, las cuales utilizan la criptografía como medida de seguridad para garantizar las transacciones, y más concretamente la tecnología de cadena de bloques, conocida en inglés como blockchain, que extrapolada al mundo de la contabilidad pudiera llegar a compararse con el libro de diario donde se recogen todas las transacciones. ${ }^{6}$

Gracias a la tecnología en que se fundamentan, las criptomonedas no necesitan de institución alguna que las controle, o la figura de prestamista de última instancia, esto es, los banqueros centrales, tan distorsionadores

6 Para más información, consultar https://economipedia.com/definiciones/criptomoneda.html 
para el mercado. Entre las características de las criptomonedas se pueden señalar, entre otras:

- La instantaneidad de la transferencia de una cuenta a otra, situadas ambas en cualquier parte del mundo.

- La innecesaria existencia de intermediarios en las negociaciones, con la reducción de costes de transacción que ello conlleva.

- La seguridad que sustenta cada una de las transacciones.

- El tamaño que ocupan, ya que pueden almacenarse en un dispositivo de memoria portable.

Entre las distintas criptomonedas la más conocida es la denominada bitcoin, que tiene su origen en 2009, cuando fue creada por Satoshi Nakamoto (pseudónimo de su autor o autores) con el objetivo principal de utilizarse como medio de pago para compras a través de internet.

El mayor inconveniente que presentan las criptomonedas para convertirse en el medio de pago más aceptado ahora mismo es su alta volatilidad, dado que, por ejemplo, en los últimos seis meses ha pasado de valer menos de 25 mil dólares americanos por bitcoin, hasta llegar a superar los 63 mil, para encontrarse actualmente cerca de los 35 mil.

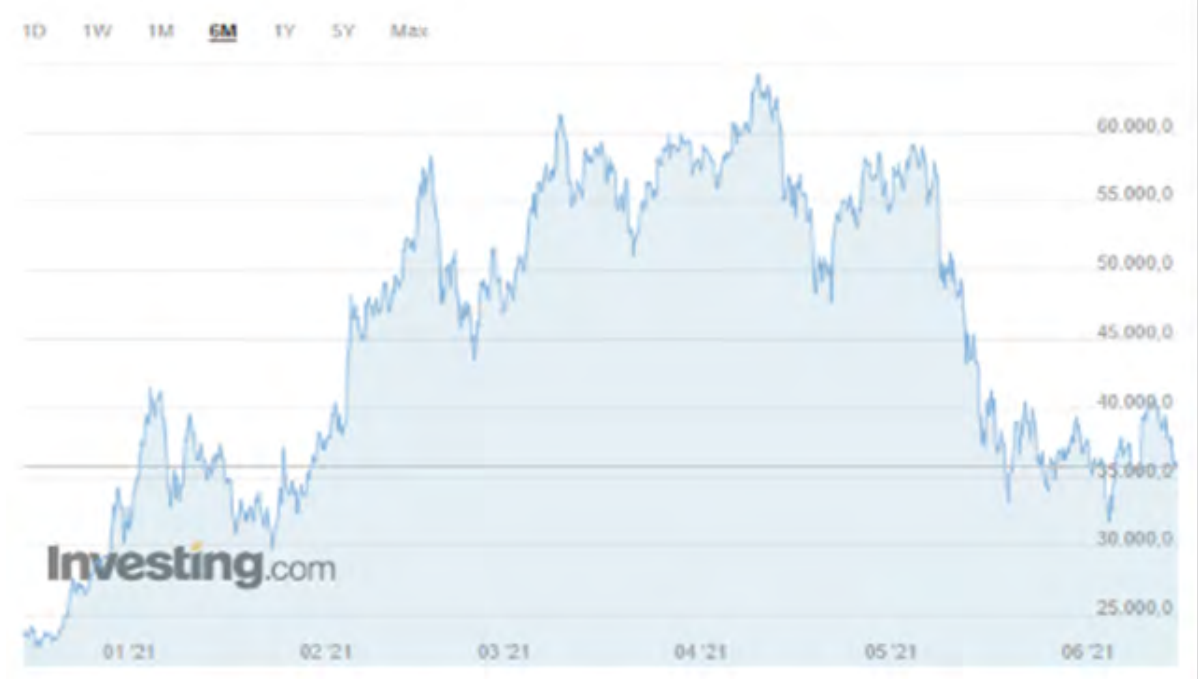

Otro de los inconvenientes que hoy día ofrece el bitcoin es que nada se referencia en dicha unidad, esto es, cualquier transacción que se hace respecto al valor del bitcoin hay que trasladarla automáticamente a dólares, euros o cualquier otra moneda, para poder hacerse a una idea más precisa de su valor.
Figura 1. Comportamiento del bitcoin el en período enero-junio de 2021.

Fuente: investing.com (consulta realizada el 19-06-2021). 
Actualmente, el bitcoin y las otras monedas digitales, pese a que son demandadas con gran interés, no pueden usarse como medio de intercambio, sino más como objeto de especulación, vista la oscilación que han sufrido sus cotizaciones a lo largo del último año. No obstante lo anterior, si su cotización llegase a estabilizarse y la gente comenzara a "pensar" en bitcoins, no se descarta que pudiera llegar a convertirse en un efectivo medio de pago, si bien lo que nunca podría llegar a ser es dinero, y seguidamente explicamos el motivo de nuestra afirmación.

En principio, el bitcoin no podrá convertirse en dinero principalmente porque no tiene bien material que lo sustente; pudiera incluso darse el caso de que, ante una bajada de su cotización, en un caso extremo podría llegar a desmonetizarse en su totalidad. Por el contrario, respecto al dinero que está respaldado por un bien material, en caso de la pérdida absoluta de su valor económico, en última instancia siempre quedaría el valor que subjetivamente la gente le otorgue como medio de uso.

Por la misma causa, otra condición fundamental que no cumplen las criptomonedas es la de no haber disfrutado en primera instancia de un valor de uso reconocido de manera consuetudinaria por la sociedad a lo largo del tiempo como medio de intercambio, de manera que a partir de ahí, y con el paso de un prolongado proceso de prueba y error, adquiriera la condición de dinero. En este sentido, ninguna criptomoneda tiene valor de uso de por sí, y por tanto el teorema regresivo de Mises antes enunciado sería de imposible cumplimiento.

El bitcoin pretende muy convenientemente simular ciertas condiciones que se verifican en el dinero mercancía, como lo demuestra el límite fijo máximo de emisión de bitcoins, que supuestamente está estipulado en 21 millones de dólares, cantidad que se estima se alcanzará en el año 2140, de modo similar a como la naturaleza nos brinda una cantidad fija de oro, la total existente en el planeta. También se hace uso de cierta terminología, como por ejemplo, dado que por minero tradicionalmente entendemos a aquella persona que trabaja para extraer el material que se contiene en una mina, del mismo modo las personas que realizan complejos cálculos computacionales para ir liberando bitcoins reciben la misma denominación, y su acción es calificada como "proceso de minería de bitcoins". 


\section{El dinero en una sociedad libre}

La primera medida a adoptarse en una sociedad libre respecto al dinero debe ser la de suprimir el monopolio de emisión que actualmente ostenta el poder político, por lo que la emisión de dinero deberá de privatizarse. La siguiente medida a adoptar sería la de la eliminación de los entes planificadores relacionados con el dinero y el sistema financiero, esto es, los bancos centrales. En tercera instancia, habría que someter a los agentes implicados en el sistema financiero a los principios generales del derecho.

Los distintos gobiernos, en toda la extensión del globo terráqueo, se han ocupado de adulterar y emitir las cantidades de dinero ajustadas en cada momento a sus necesidades, sin tener en cuenta la inflación o depreciación del valor de la moneda que ello ha supuesto para los ciudadanos; por si esto no fuera suficiente, "han acostumbrado a usar la emisión de moneda a lo largo de la historia como un medio de propaganda político al incluir el retrato de los distintos reyes, emperadores o dictadores en las diferentes monedas" (Bastos, 2020, p. 33).

En una sociedad libre, los diferentes emisores de moneda competirían entre ellos de igual manera que lo hacen los proveedores de cualquier otra mercancía. Ante esa tesitura, los distintos agentes, dotados de información de primera mano, decidirían la moneda más conveniente acorde a sus intereses, y la moneda que no resultara elegida por ser de peor calidad, o por el motivo que fuere, se iría apartando del mercado, pudiendo llegar a generalizarse aquella que tuviera una mayor aceptación, hasta el punto de convertirse, en un momento futuro, en un patrón monetario. Como recuerda el profesor Huerta de Soto (2016), el dinero es una institución social que surge de forma espontánea, de igual forma que el derecho, o el lenguaje, y conlleva un enorme volumen de información, por lo que de manera evolutiva a lo largo de un periodo de tiempo en el que se ven inmiscuidas diferentes generaciones de personas, y por medio del método de ensayo-error, subsistirán aquellas monedas que mejor satisfagan la cooperación social.

Por otra parte, en una sociedad libre se podría dar la paradoja de que cualquiera podría convertirse en emisor de dinero, pero casi nadie podría cumplir los requisitos para ello, de ahí que se entienda que lo más prudente, en primera instancia, sería la vuelta al último patrón aceptado de forma consuetudinaria por la sociedad, esto es, el patrón oro. En consecuencia, y retomando a Huerta de Soto, habría que: 
[...] privatizar el dinero actual sustituyéndolo por su equivalente metálico en oro, y dejando que el mercado retome su libre evolución a partir del momento de la transición, bien confirmando al oro como dinero de general aceptación, o bien dando entrada de manera espontánea y paulatina a otros patrones monetarios $(2016$, p. 576$)$.

No obstante lo anterior, nada imposibilitaría que alguien estableciera, si así lo deseara, un banco con reserva fraccionaria, con el coeficiente de caja que estime suficiente para hacer frente a las diferentes obligaciones contraídas. Sin embargo, de la misma forma que ese alguien podría establecer el banco como estimase, el resto de la ciudadanía no tendría obligación alguna de aceptar sus billetes como medio de pago.

También podría darse el caso de que coexistieran diversas formas de dinero y convivieran en competencia, por ejemplo, distintos patrones metálicos, como el oro y la plata, o cualquier otro que la sociedad de manera consuetudinaria decidiera adoptar.

Lo más importante de privatizar el dinero sería que este dejaría de ser un instrumento en manos del Estado, con las potenciales consecuencias y malos usos que ello conlleva, porque, como ya señaló Lenin, para acabar con el capitalismo el mejor procedimiento es acabar con la moneda (citado en Bastos, 2020, p. 34).

\section{Conclusiones}

En este artículo hemos realizado una breve radiografía histórica y evolutiva de los intercambios y el dinero, introduciendo aspectos de actualidad como las criptomonedas. Pero nos gustaría también lanzar una serie de juicios y reflexiones, que pueden servir para posteriores líneas de investigación más exhaustivas. Proponemos las siguientes cuestiones, que podrán ser objeto de estudio por separado o de forma conjunta:

- El tamaño de la economía financiera.

- El sistema financiero, en particular el papel de los bancos centrales y de los bancos comerciales.

- El analfabetismo monetario.

- El papel e influencia de la tecnología en los mercados financieros, principalmente en el bancario. 
El papel de la economía financiera, dentro del actual marco económico que nos está tocando vivir, resulta cuando menos perverso. El volumen de esta respecto de la economía real es difícil de determinar, entre otros aspectos por su peso y complejidad. También podríamos añadir que cada vez existe más distancia con respecto al ciudadano medio, y pareciera que se ha dejado de lado el aspecto productivo de la economía, cuando es este el responsable directo de la producción de bienes y servicios.

Como hemos ido indicando a lo largo del artículo, el dinero es la institución clave para el desarrollo de las sociedades, pero la actual deriva nos lleva a replantearnos el excesivo peso preponderante que ha tomado. Podemos señalar, entre otros instrumentos, por ejemplo, el de la titularización, que hace realmente confusa la trazabilidad que puede sufrir un activo financiero, cuando además el proceso se vuelve a complicar porque se "paquetiza" en otros y el nuevo producto resultante se pasa a denominar de forma ininteligible.

Lo que queremos dar a entender es que parte de esta dinámica que ha tomado la economía financiera se debe, desgraciadamente, más a un componente especulativo que a uno de generación de riqueza.

El sistema financiero moderno está constituido por una gran variedad de agentes y organismos, entre los cuales podemos destacar a los bancos centrales y a la banca comercial, sin olvidarnos tampoco de la banca de inversión, las aseguradoras, las agencias de rating y las gestoras de fondos, entre otras. Todo estos organismos conforman un magma sumamente complejo y al mismo tiempo sutil, dado que existen una gran variedad de productos, con acrónimos desconocidos que hacen que el dinero como medio comúnmente aceptado se camufle tras ellos, desvirtuando sus auténticas funciones.

Esto aparentemente podría entenderse como desarrollo, a futuro, pero infortunadamente, los sucesos y hechos económicos de los últimos cincuenta años indican lo contrario: tensiones en los mercados monetarios, recesiones y crisis económicas han sido características de nuestros tiempos. Y, sobre todo, no debemos olvidar la gran recesión sufrida en 2008.

Difícilmente los intercambios pueden funcionar de acuerdo con las leyes del libre mercado, incentivando la creatividad empresarial, la cooperación social y respetando los principios generales del derecho, si el bien utilizado para los mismos (el dinero) se pervierte, se manipula y se somete a una excesiva regulación normativa, todo ello siempre orientado a salvaguardar los intereses de los poderes públicos y de una minoría social, los 
denominados grupos de interés. Si además de esta manipulación legislativa y del capricho de los gobernantes, esto se oculta, se confunde y se camufla al público en general, el resultado evidentemente no es eficiente para la economía de mercado.

Por ejemplo, podríamos traer a colación el papel de los bancos centrales: ¿realmente los individuos que conforman la sociedad saben lo que son y lo que hacen? ¿Entienden su funcionamiento y las consecuencias de sus políticas y sus decisiones? Permanentemente se escucha en los medios que sus actuaciones son algo bueno, los representan como los solucionadores de los problemas monetarios y económicos, y no como generadores de estos. Seguramente, la centralidad que nos está tocando vivir a los europeos, por ejemplo, desde la constitución de la Unión Europea y del Banco Central Europeo, hace que precisamente a nivel individual tengamos unos impedimentos que nos impiden ver lo que suponen las actuales políticas monetarias, y en cambio las padecemos constantemente de forma negativa cuando desarrollamos nuestra actividad económica. Esta centralidad contribuye a hacer de los instrumentos y organismos financieros algo demasiado grande, complejo y burocratizado, para que el ciudadano medio ni tan siquiera sea capaz de comprenderlo mínimamente.

No todo es malo, por supuesto. Pero nuestra perspectiva nos tiene que hacer valorar todo el fenómeno en términos relativos, y es aquí donde, para nosotros, los efectos negativos son superiores a los positivos. Crear dinero de la nada, sin respaldo de ahorro voluntario, no es una pauta recomendable para un crecimiento sostenido. Sin duda, a corto plazo y para algunos, los primeros en recibirlo, no es algo desdeñable, pero en términos generales, para la sociedad en conjunto, sus efectos son negativos en términos relativos.

Por otra parte, el grado de analfabetismo monetario en la sociedad actual preocupa. Por ejemplo, abrir ahora una cuenta corriente en un banco resulta un proceso complejo, tedioso y arduo. No se trata de hablar del tantundem, o de profundizar si el depósito a la vista no es un contrato de depósito y sí de préstamo, cuestión por otro lado realmente importante. Lo que se pretende muchas veces es confundir y de esta forma librarse de preguntas o impedir que se generen situaciones embarazosas para los poderes públicos y las autoridades monetarias, más aún cuando se busca generar costumbre por medio de la práctica, evitando de esta forma que se produzca un replanteamiento del funcionamiento del sistema. Es este un círculo vicioso, del cual resulta muy difícil salir. 
Un ciudadano medio, ¿es consciente de lo que firma al abrir una cuenta corriente? Creemos que la respuesta es no. La confusión se establece además cuando se violan los principios generales del derecho y no solamente no se ha cobrado por la custodia sino que se ha pagado (hasta ahora como práctica general). Es posible que podamos pensar que nuestro dinero depositado a la vista pueda llegar a estar disponible, cuando en realidad dicha disponibilidad es dudosa. Las autoridades lo permiten, y aparecen en nuestras vidas para tranquilizarnos y decirnos que, en caso de "problemas", se encargarán de dar respuesta, ¡cuando el problema lo han generado ellas mismas!

La cuestión que nos planteamos es que si no somos capaces de entender la realidad monetaria, difícilmente podremos revindicar cambios en el sistema. Más aún, cuando nos confunden para pensar que el origen de los mismos problemas se encuentra en otras causas que las propias endógenas del sistema. Por eso, creemos necesario formar adecuadamente a los individuos para comprender los principios básicos monetarios. Educar de forma responsable a las nuevas generaciones puede servir para propiciar cambios al sistema y exigir responsabilidades y políticas eficientes, evitando la demagogia a la hora de situar y presentar la discusión y el análisis del problema.

La sociedad contemporánea discurre a gran velocidad, y el día a día de nuestro estilo de vida, junto con una tecnología cada vez más sofisticada y compleja, hace que el dinero aparezca como imprescindible, y al mismo tiempo sea una incógnita lo que hay detrás del mismo. Ante esta tecnología estamos sometidos, y ella nos hace más esclavos del control gubernamental. Un ejemplo que traemos a colación es el aspecto de la disminución de pagos en efectivo, lo cual no beneficia a las personas, pero sí a las autoridades, ya que de esta forma se les proporciona un mayor control sobre nuestras vidas, finanzas y hábitos de consumo e inversión. A su vez, y sin darnos cuenta, la tecnología incrementa también la brecha del conocimiento, por lo que consecuentemente el analfabetismo monetario es mayor. La propia complejidad del funcionamiento financiero induce a ello.

Para finalizar, hemos comentado brevemente aspectos de tecnología, analfabetismo monetario, perversión financiera, regulación excesiva y bancos centrales, sabiendo que tan solo son unas breves pinceladas que pudieran ser la base para posteriores artículos más extensos. Todo esto se hace con el objeto de intentar traer, aquí y ahora, la realidad del dinero. Lejos quedan las bolsas con monedas de oro y plata, o las cabezas de ganado usadas como dinero en las sociedades antiguas. Pero en cambio, paradójicamente, 
sabemos bastante menos que los mesopotámicos o los fenicios acerca de la economía financiera (monetaria) y de cómo esta nos afecta en nuestro día a día, sin darnos cuenta de que el circulo vicioso de ignorancia, complejidad y perversión no podemos romperlo. Quizás queda por invocar un hechizo que llame a las fuerzas del mercado, lo cual pudiera ser la solución para volver a dotar al dinero de sus verdaderas funciones.

\section{Referencias}

Aguirre, J. A. (2019). El misterio del dinero. Unión Editorial.

Bastos, M. A. (2020). Sobre el anarcocapitalismo. Editorial Innisfree.

Böhm-Bawerk, E. (2005 [1959]). La ley básica de determinación del precio. En J. Huerta-de-Soto (coord.), Lecturas de Economía Política (volumen I, pp. 99-142). Unión Editorial.

Conesa, C. (2019). Bitcoin: ¿Una solución para los sistemas de pago o una solución en busca de problema? [Documentos Ocasionales n. $\left.{ }^{\circ} 1901\right]$. Banco de España. https://www.bde.es/f/webbde/SES/Secciones/ Publicaciones/PublicacionesSeriadas/DocumentosOcasionales/19/ Fich/do1901.pdf

Franch-Parella, J. (2012). Economía. Unión Editorial.

Huerta-de-Soto, J. (2000). La escuela austriaca, mercado y creatividad empresarial. Editorial Síntesis.

Huerta-de-Soto, J. (2012). La esencia de la Escuela Austriaca. Universidad Francisco Marroquín.

Huerta-de-Soto, J. (2015 [1992]). Socialismo, cálculo económico y función empresarial. Unión Editorial.

Huerta-de-Soto, J. (2016 [1998]). Dinero, crédito bancario y ciclos económicos. Unión Editorial.

Hülsmann, J. G. (2008). The ethics of money production. Mises Institute.

Hülsmann, J. G. (2021). La ética de la producción del dinero. Unión Editorial. Martínez-Meseguer, C. (2015a [2006]). La teoría evolutiva de las instituciones. Unión Editorial. 
Martínez-Meseguer, C. (2015b). Algunas aclaraciones sobre el dinero y el sistema financiero desde la perspectiva de la EAE. MARTINEZMESEGUER [Entrada de blog]. https:// martinezmeseguerblog.wordpress.com/2015/12/07/algunasaclaraciones-sobre-el-dinero-y-el-sistema-financiero-desde-laperspectiva-de-la-eae/

Martínez-Meseguer, C. (2017). Aclaraciones, definiciones y críticas respecto de las teorías de la utilidad, el valor y los precios (la validez de las aportaciones de Carl Menger en la actual Escuela Austriaca de Economía. Procesos de Mercado, XIV(1), 87-120.

Menger, C. (1985 [1892]). El origen del dinero. Revista Libertas, 2, 1-17. http://www.eseade.edu.ar/files/Libertas/48_7_Menger.pdf

Menger, C. (1996 [1871]). Principios de economía política. Ediciones Folio.

Menger, C. (2006 [1883]). El método de las ciencias sociales. Unión Editorial.

Menger, C. (2013 [1909]). El dinero. Unión Editorial.

Mises, L. (2011 [1949]). La acción humana. Unión Editorial.

Mises, L. (2012 [1912]). La teoría del dinero y del crédito. Unión Editorial.

Mises, L. (2020 [1920]). El cálculo económico en la comunidad socialista. Procesos de Mercado, XVII(2), 353-388.

Rallo, J. R. (2015). Contra la Modern Monetary Theory. Unión Editorial.

Röpke, W. (1974 [1937]). Introducción a la economía política. Unión Editorial.

Rothbard, M. N. (2011 [1962]). El hombre, la economía y el Estado. Unión Editorial.

Rothbard, M. N. (2013 [1995]). Historia del pensamiento económico. Unión Editorial.

Rothbard, M. N. (2015 [1966]). What has government done to our money? Mises Institute. 